\title{
Relationship Between Anterior Commissure and Corpus Callosum Size and Human Intelligence in Brain MRI of Healthy Volunteers
}

\author{
Abdulrasool Alaee ${ }^{1,{ }^{*}}$, Reza Zarei ${ }^{1}$, Samaneh Farnia ${ }^{2}$ and Mohammad Khademloo ${ }^{3}$ \\ ${ }^{1}$ Department of Radiology, Imam Khomeini Hospital, Mazandaran University of Medical Sciences, Sari, Iran \\ ${ }^{2}$ Psychiatry and Behavioral Sciences Research Center, Addiction Institute, Mazandaran University of Medical Sciences, Sari, Iran \\ ${ }^{3}$ Department of Community Medicine, Mazandaran University of Medical Sciences, Sari, Iran \\ "Corresponding author: Department of Radiology, Imam Khomeini Hospital, Mazandaran University of Medical Sciences, Sari, Iran. Tel: +98-9111515116, Email: \\ aalaeei@mazums.ac.ir \\ Received 2018 January 24; Revised 2019 May 14; Accepted 2019 May 20.
}

\begin{abstract}
Background: The parieto-frontal integration theory of intelligence revealed a novel scope of investigation examining how performance networks are related to structural networks in the brain.

Objectives: These investigations highlighted the role of brain commissures, but no evaluation has been performed examining the anterior commissure (AC) in determining the level of intelligence.

Patients and Methods: A total of 100 healthy volunteers were selected, and their brain MRIs were acquired. Measurements were performed for the AC and the corpus callosum (CC) on MRI. Intelligence quotient (IQ) was calculated using the Wechsler Adult Intelligence Scale-R(WAIS-R). $\mathrm{P}<0.05$ was considered significant.

Results: The average age of men was $32.58 \pm 8.84$ years, and the average age of women was $32.88 \pm 7.83$ years. The average IQ of volunteers in the study was $103.57 \pm 4.178$. Partitioning the subjects by gender did not lead to significant results. No significant correlation was determined between the dimensions of AC and IQ. The height of the CC had a positive correlation with IQ. However, the thickness of the genu, body, and splenium of the CC demonstrated no significant relation to IQ.

Conclusion: The AC had no clear relationship with IQ, although it may have a role in women. The height parameter of the CC had a significant correlation with IQ, suggesting the interference between the anterior and posterior parts of the brain in the human intelligence process.
\end{abstract}

Keywords: Brain, Anterior Commissure, Corpus Callosum Fiber Development, Gender, IQ, MRI

\section{Background}

The improvement of modern cerebral imaging modalities and the advent of analysis processing data technologies have enabled the examination of the neurobiological nature of intelligence (1-3).

Following the introduction of the parieto-frontal integration theory of intelligence by Jung and Haier, there has been a new strand of intelligence studies that focuses on the investigation of the correlation between the anatomical and functional frameworks of the brain $(4,5)$. As explained by Banich and Belger, interhemispheric transferring is beneficial for performing tasks that demand a high level of attention, but such interaction is not necessary for simple tasks with low demand (6). Brown and Banich also argued that simple tasks are performed by only one hemisphere and that more complex tasks involve interactions between the two hemispheres (7-10). The anterior commissure $(\mathrm{AC})$ is a secondary interhemispheric communication that exists in all mammals. This structure connects the temporal lobes and amygdala in the two hemispheres and is involved in memory, sensation, speech, hearing and sexual behavior. The AC carries all fibers originating from the neocortex in marsupials, while in placental mammals, the AC conveys only some of the nervous tracts $(11,12)$. Studies have also shown that the AC could be a compensatory pathway in patients with corpus callosum agenesis (13). Most likely, both the AC and the corpus callosum (CC) have some similar functions in brain neural transfer. A multitude of studies suggested that a larger CC confers greater intellectual abilities $(9,10,14-17)$. This positive relationship between the thickness of the corpus callosum and full scale intelligence quotient (IQ) may be an indication of more or better myelinated nerve fibers that enable interhemispherring data transferring across the corpus callosum, which is probably useful for integrating and processing data (3).The findings of other researches also showed no re- 
lationship between CC size and IQ $(4,7,18,19)$. In spite of these studies, associations have not yet been proven.

According to evolution theory, the CC is a newlycreation only in placental mammals (20). However, it is not observed in most of these animals. Unlike the AC as the primary mode of communication between the hemispheres, the CC is not observed in marsupials (21). The function of the AC is yet unknown and its size has not been investigated in relation to human intelligence. However, dysfunction in these white matter fibers have been stated in pediatric bipolar disorder and chronic schizophrenia (22). This study aimed to determine the correlation between the measure values of the AC, CC and intelligence.

\section{Objectives}

These investigations highlighted the role of brain commissures, but no evaluation has been performed examining the $\mathrm{AC}$ in determining the level of intelligence.

\section{Patients and Methods}

This study was performed at the hospitals between January 2017 and September 2017. After approval was obtained from the ethical committee, 100 healthy right-handed volunteers aged 18 to 45 years were invited to participate in the study. Patients were enrolled in the study if they wished, after completing the consent form. All participants were screened through a self-report questionnaire and the Structured Clinical Interview for DSM-IV disorders (SCID) by a psychiatrist before entering the study. Exclusion criteria were any history or current diagnosis of head trauma and organic or neurological diseases (seizure disorder), intellectual disability, psychiatric disorders (mood or psychotic disorders, and cognitive impairment), alcohol, smoking and substance abuse, and use of psychiatric medications.

All volunteers with normal brain MRI results were enrolled. All images were acquired on a 1.5T MRI (General Electric, USA), transverse and sagittal slices of T2-weighted fast spin-echo sequences with these parameters: repetition time/echo time $=3500$ millisecond $/ 85$ millisecond, voxel size $=1 \mathrm{~mm}^{3}$, and 128 contiguous $1.5 \mathrm{~mm}$. All images were obtained in standard positions. Measurements were also taken for anterior-posterior and superior-inferior diameters of the AC (Figure 1) on the mid-sagittal plane, and the transverse diameter of the AC was measured on the axial images (23) (Figure 1). A variety of approaches have been introduced to measure the corpus callosum. However, we chose a manual technique that was conducted by two radiologists simultaneously. To measure the dimensions of the CC on mid-sagittal images, a line was drawn from the anterior-most point of the CC to the posterior-most point, and the other line was drawn from the superior to the inferior part of the CC perpendicular to the first line. The length of the CC was equal to the size of the first line and the height was equal to the size of the second line (Figure 2). According to the maximum straight length of the CC by Witelson's method, it is categorized into three zones. The genu, body and splenium portions of CC were divided as anterior, middle and posterior third, respectively (24). The thickness of the genu, body and splenium were measured at the midportion of each zone (Figure 2).

Patients' demographic information, such as age, gender, and handedness, was gathered. Measures of IQ were taken using the Wechsler Adult Intelligence Scale-R(WAISR). After an MRI was performed for every subject, the WAIS$\mathrm{R}$ scores were calculated by a clinical psychologist under the supervision of a psychiatrist who was unaware of the MRI results. The validity and reliability of the Persian version of the WAIS-R were studied in Iran. The WAIS-R subscales showed their internal consistencies were 0.77 to 0.88 with split-half coefficients, and reliability from 0.69 to 0.87 on test-retest stability $(25,26)$.

\subsection{Statistical Analysis}

Data were recorded in SPSS 20 software (IBM Corp. Released 2011. IBM SPSS Statistics for Windows, Version 20.0. Armonk, NY). The correlation coefficient (Pearson) was used for quantitative sample data to measure how the two variables were linearly correlated and dependent. Adjustments for age and sex were made using partial correlations. A P value of $<0.05$ was also considered significant.

\section{Results}

A total of 100 healthfully candidates were enrolled (male/female ratio 50/50; age range 18 to 45 years; mean age $32.73 \pm 8.11$ years). The average age of men and women were $32.58 \pm 8.84$ years and $32.88 \pm 7.83$ years, respectively. There was no statistically significant age difference by gender. ( $\mathrm{P}=0.854)$. The average IQ of all participants in this study was $103.57 \pm 4.178$ (range 90 to 116 ). The average IQ was $101.84 \pm 4.093$ (range $90-109$ ) in men and $105.30 \pm$ 3.524 (range 99 - 116) in women $(P=0.627)$.

Correlations between each diameter of the AC and IQ were analyzed in the total sample for men and women (Table 1).

The superior-inferior diameter of the AC in the combined sample showed a negative correlation with IQ, which was maintained after removing the effect of age. When this parameter was analyzed for gender, we observed a negative correlation in men, while women had a negative 

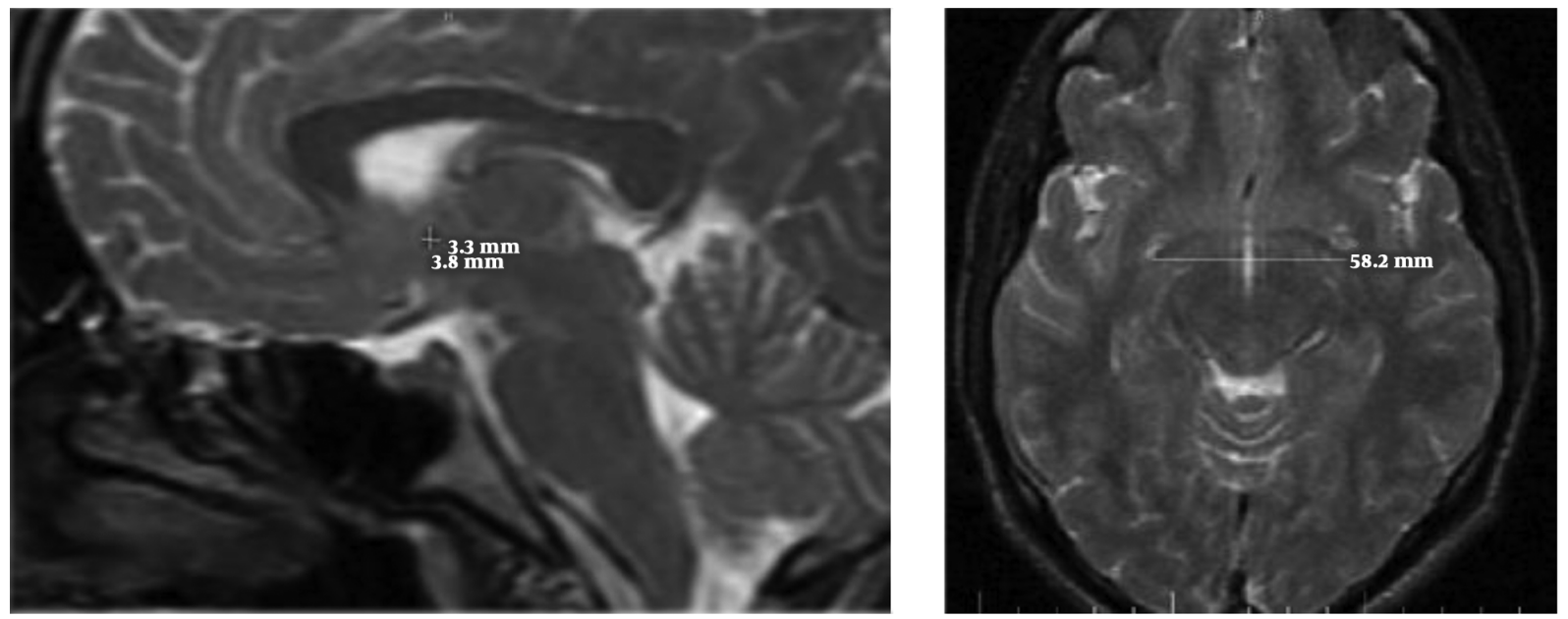

Figure 1. How to measure the superior-inferior and anterior-posterior diameter of the anterior commissure (AC) and the transverse diameter on MRI.
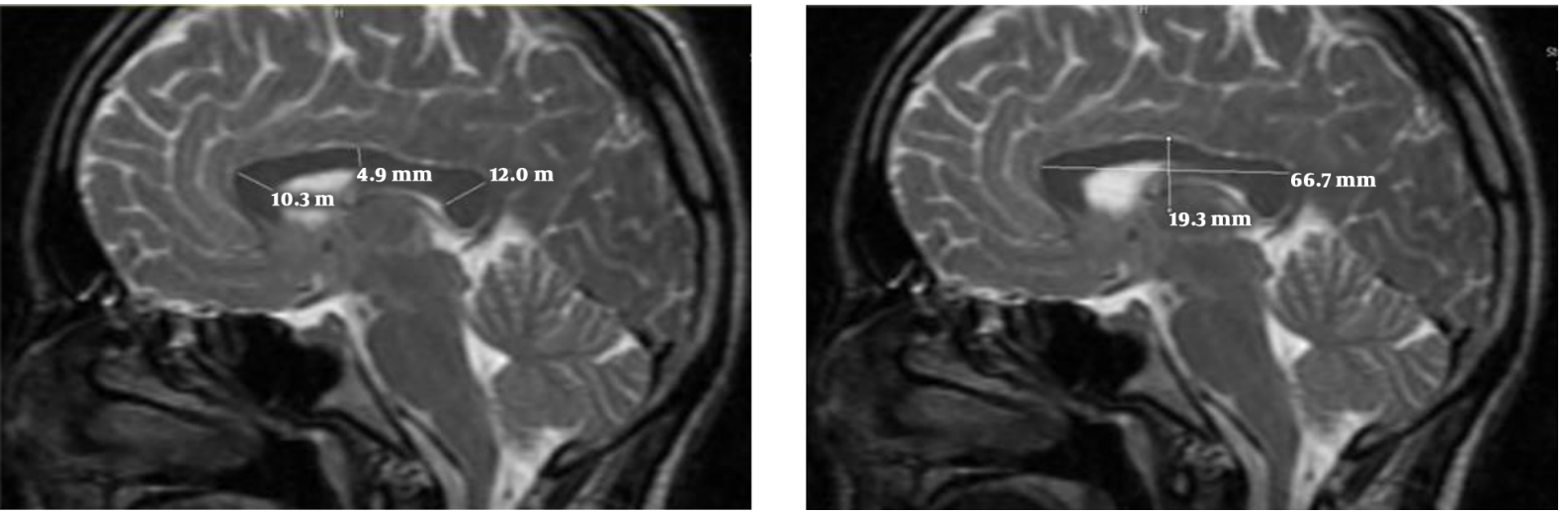

Figure 2. How to measure the length and height of the corpus callosum (CC) and the thickness of the genu, body and splenium of the CC on MRI.

relationship similar to that of the combined sample but with more intense and significant levels.

The anterior-posterior diameter of the AC does not show a significant correlation with IQ before adjusting for the effect of age. However, after removing the effect of age, this negative correlation was not only significant, but its values also increased. When this parameter was analyzed by gender, we observed a negative correlation in men and a positive correlation in women, while the correlation increased in both samples after removing the effect of age. Transverse diameter measurements of the AC for all three samples demonstrated no significant relationship between the transverse diameters of the $\mathrm{AC}$ and $\mathrm{IQ}$, in contrary to the trend towards a negative relationship.

The relationship between the length and height of the CC and the calculations of IQ is shown in Table 2.

The CC height showed a significant positive correlation with IQ, but this correlation was not significant after removing the effect of age. When this relationship was analyzed based on gender, the male sample showed a significant positive correlation. However, after adjustment for age, this correlation disappeared. The CC length demonstrated a negative correlation with full scale IQ, such that even after adjustment was made for age, the partial correlation was not only maintained, but the value of that correlation also showed an increase. The correlation between the thickness of the CC and estimations of IQ is shown in Tables 3 and 4 .

When the thickness of the three parts of the CC, the genu, body, and splenium, were assessed on behalf of the anterior, middle and posterior CC, no significant correlation was determined between the thicknesses of each of these areas and IQ. 


\begin{tabular}{|c|c|c|c|c|c|}
\hline \multirow{2}{*}{$\begin{array}{l}\text { Measured parameter, Study } \\
\text { population }\end{array}$} & \multirow{2}{*}{$\begin{array}{l}\text { Mean } \pm \text { standard } \\
\text { deviation }(\mathbf{m m})\end{array}$} & \multicolumn{2}{|c|}{ Simple bivariate correlation } & \multicolumn{2}{|c|}{ Partial correlation, considering the age of the control } \\
\hline & & $\mathbf{r}^{\mathbf{a}}$ & Pvalue & $\mathbf{r}^{\mathbf{a}}$ & Pvalue \\
\hline \multicolumn{6}{|l|}{ Anterior-posterior diameter } \\
\hline men & $2.29 \pm 0.38$ & -0.283 & 0.047 & -0.357 & 0.012 \\
\hline women & $2.19 \pm 0.29$ & -0.283 & 0.046 & -0.412 & 0.003 \\
\hline Total & $2.24 \pm 0.34$ & -0.115 & 0.256 & -0.199 & 0.048 \\
\hline \multicolumn{6}{|l|}{ Superior-inferior diameter } \\
\hline men & $4.01 \pm 0.54$ & -0.169 & 0.242 & -0.580 & 0.694 \\
\hline women & $3.50 \pm 0.531$ & -0.586 & 0.001 & -0.584 & 0.001 \\
\hline Total & $3.75 \pm 0.59$ & -0.474 & 0.507 & -0.466 & 0.001 \\
\hline \multicolumn{6}{|l|}{ Transverse diameter } \\
\hline men & $52.82 \pm 3.47$ & -0.096 & 0.001 & -0.158 & 0.279 \\
\hline women & $50.04 \pm 3.34$ & -0.103 & 0.479 & -0.060 & 0.684 \\
\hline Total & $53.43 \pm 3.45$ & -0.015 & 0.885 & -0.136 & 0.179 \\
\hline
\end{tabular}

Abbreviations: AC, anterior commissure; IQ, intelligence quotient.

${ }^{\mathrm{a}}$ Bivariate (Pearson) correlation.

\begin{tabular}{|c|c|c|c|c|c|}
\hline \multirow{2}{*}{$\begin{array}{l}\text { Measured parameter, } \\
\text { Study population }\end{array}$} & \multirow{2}{*}{$\begin{array}{c}\text { Mean } \pm \text { standard } \\
\text { deviation }(\mathbf{m m})\end{array}$} & \multicolumn{2}{|c|}{ Simple bivariate correlation } & \multicolumn{2}{|c|}{ Partial correlation, considering the age of the control } \\
\hline & & $\mathbf{r}^{\mathbf{a}}$ & Pvalue & $\mathbf{r}^{\mathbf{a}}$ & Pvalue \\
\hline \multicolumn{6}{|l|}{ CC length } \\
\hline men & $69.24 \pm 3.07$ & -0.411 & 0.003 & -0.113 & 0.441 \\
\hline women & $68.65 \pm 7.38$ & -0.204 & 0.156 & -0.186 & 0.201 \\
\hline Total & $68.95 \pm 3.76$ & -0.294 & 0.003 & -0.346 & 0.001 \\
\hline \multicolumn{6}{|l|}{ CC height } \\
\hline men & $21.43 \pm 2.4$ & 0.320 & 0.023 & 0.256 & 0.076 \\
\hline women & $21.70 \pm 1.92$ & 0.098 & 0.497 & 0.201 & 0.166 \\
\hline Total & $21.56 \pm 2.17$ & 0.234 & 0.019 & 0.111 & 0.274 \\
\hline
\end{tabular}

Abbreviations: CC, corpus callosum; IQ, intelligence quotient.

${ }^{\text {a }}$ Pearson correlation coefficient.

\begin{tabular}{lccc}
\hline \multicolumn{4}{l}{ Table 3. Mean Thickness of Different Anatomical Parts of CC } \\
\hline Measured parameter & Total & Men & Women \\
\hline Genu $(\mathbf{m m})$ & $10.59 \pm 1.59$ & $11.01 \pm 1.60$ & $10.18 \pm 1.46$ \\
Body $(\mathbf{m m})$ & $4.60 \pm 1.44$ & $4.53 \pm 1.41$ & $4.68 \pm 1.49$ \\
Splenium $(\mathbf{m m})$ & $11.41 \pm 1.68$ & $11.67 \pm 1.69$ & $11.15 \pm 1.65$ \\
\hline
\end{tabular}

Abbreviation: CC, corpus callosum.

${ }^{\mathrm{a}}$ Values are expressed as mean $\pm \mathrm{SD}$.

\section{Discussion}

This study showed that the superior-inferior diameter of the AC, before and after the exclusion of the effect of age, and the anterior-posterior diameter of the AC, only after excluding the effect of age, showed a significant negative correlation with IQ, but no significant correlation was determined between the transverse diameter of the AC and IQ.

In this study, the height of the CC had a positive correlation with IQ, and the length of the CC possessed a negative relationship although the thickness of the genu, body, and splenium of the CC showed no significant correlation with IQ.

To check whether the correlation between the length of the CC and IQ had an association with gender, the correlation was examined separately for each sex. The results showed that men had a greater correlation coefficient compared to the total sample, while compared to the total sample; the correlation in women was lower and not significant. In several previous studies, sexual dimorphism had been demonstrated in terms of gender discrepancies in the shape of the corpus callosum, cerebrum and brain metabolism, as determined from measurements of cognitive functions (27-32).

The results of a study by Mohammadi et al. did not show remarkable sexual dimorphism in human CC parameters in North Iran. However the parameters of the CC in males were higher than in females (24).

The anterior commissure, like the corpus callosum, is 


\begin{tabular}{|c|c|c|c|c|c|c|}
\hline \multirow{2}{*}{$\begin{array}{l}\text { Measured } \\
\text { parameter }\end{array}$} & \multicolumn{2}{|c|}{ Correlation in total sample } & \multicolumn{2}{|c|}{ Correlation in men } & \multicolumn{2}{|c|}{ Correlation in women } \\
\hline & $\mathbf{r}$ & Pvalue & $\mathbf{r}$ & Pvalue & $\mathbf{r}$ & Pvalue \\
\hline Genu (mm) & -0.130 & 0.197 & -0.153 & 0.288 & 0.143 & 0.321 \\
\hline $\operatorname{Body}(\mathbf{m m})$ & 0.141 & 0.162 & 0.1110 & 0.443 & 0.154 & 0.287 \\
\hline
\end{tabular}

Abbreviation: CC, corpus callosum; IQ, intelligence quotient.

a white-matter tract to bond the two hemispheres of the brain. The measurement of the superior-inferior diameter of the AC can be an index of the height of the CC and the degree of neural fiber myelination and crowding. Thus, the negative relationship between the superior-inferior diameter of the AC and IQ may confirm the hypothesis that higher intelligence is accompanied by less interhemispheric transferring. The anterior-posterior and especially the superior-inferior diameters of the AC showed negative correlations with IQ, even with adjustment for age. The decreased positive correlation of the anterior-posterior diameter of the AC and the increased negative correlation of the superior-inferior diameter of the AC with increasing age in females shows that the role of this structure reduces over the course of a lifetime. Therefore, it seems that the AC causes women to have more interaction at a younger age.

At present, two theories indicate a relationship between intelligence and brain mechanisms. The first theory states that intelligence related to the anterior portion of the cerebrum is linked to parts of the rostrum, genu and the anterior body of the corpus callosum.

The first theory is an old hypothesis that suggests that the prefrontal cortex is related to a strong intelligence. In addition, the new theory, parieto-frontal integration theory, confirmed this subject by re-highlighting the function of both the frontal lobe and parietal lobe.

The second theory is the correlation between intelligence and the posterior parts of the brain that are linked to the posterior part of the body, isthmus and splenium of the corpus callosum. It can be argued that the correlation between the CC and IQ, except for the role of CC dimensions in the level of intelligence, which is an anatomical phenomenon, may be a function of the thicker CC parts being less than the thinner parts.

A study by Luders and colleagues reported a significant positive correlation between IQ and the thickness of the CC over the posterior sections (posterior body, isthmus, and splenium) (16).

In the present study, similar to the results reported by Luders, a positive correlation was determined between IQ and full CC height as well as posterior sections of the CC in all samples (total, men and women). In contrast, the study of Allin et al. marked that higher IQ was related to a smaller posterior part of the CC in adolescents (average age of 15 years) and adulthood (average age of 22 years) (19). One possible explanation for the differences between the two studies could be attributed to the age range of participants. As CC is responsible for growth and development all through adolescence and the beginning of adulthood, it could be expected that the correlation between CC size and IQ is highly related to age. The dynamic nature of CC related to intelligence may mostly discuss heterogeneous results in researches which vary due to age, sex and socioeconomic conditions during the lifetime with multiple evolution effects. However, the CC is not essential for normal and simple tasks but is rather necessary for more complex processes (33). Therefore, the normal anterior commissure even with its enlargement, cannot carry entirely interhemispheric transferring due to gross diversity origination of callosal and anterior commissure bundles (34).

Some limitations of our study should be noted. First, verbal and performance IQ were not analyzed separately. This study was limited to the assessment of IQ and the use of structural MRI. Future studies with other neuropsychological tests for evaluating other cognitive domains and multimodal neuroimaging techniques could be helpful.

In conclusion, we suggest studying $\mathrm{AC}$ as well as $\mathrm{CC}$ in order to understand intelligence in terms of communication between the hemispheres, especially in women.

\section{Acknowledgments}

We thank the distinguished colleagues in the Mazandaran University of Medical Sciences.

\section{Footnotes}

Authors' Contributions: Abdulrasool Alaee developed the original idea and the protocol, wrote the abstract and main manuscript. Mohammad Khademlou analyzed data. Samaneh Farnia and Reza Zarei contributed to the development of the protocol, abstracted data, and prepared the manuscript. 
Conflict of Interests: There is no conflict of interest.

Ethical Approval: This study was performed at the hospitals between January 2017 and September 2017 and approval was obtained from the Ethical Committee of Research Chancellor of Mazandaran University of Medical Sciences.

Funding/Support: There was no funding/support for the study.

\section{References}

1. Colom R, Karama S, Jung RE, Haier RJ. Human intelligence and brain networks. Dialogues Clin Neurosci. 2010;12(4):489-501. [PubMed: 21319494]. [PubMed Central: PMC3181994].

2. Deary IJ, Penke L, Johnson W. The neuroscience of human intelligence differences. Nat Rev Neurosci. 2010;11(3):201-11. doi: 10.1038/nrn2793. [PubMed: 20145623].

3. Luders E, Narr KL, Thompson PM, Toga AW. Neuroanatomical correlates of intelligence. Intelligence. 2009;37(2):156-63. doi: 10.1016/j.intell.2008.07.002. [PubMed: 20160919]. [PubMed Central: PMC2770698].

4. Jung RE, Haier RJ. The Parieto-Frontal Integration Theory (P-FIT) of intelligence: Converging neuroimaging evidence. Behav Brain Sci. 2007;30(2):135-54. discussion 154-87. doi: 10.1017/S0140525X07001185. [PubMed: 17655784].

5. Vakhtin AA, Ryman SG, Flores RA, Jung RE. Functional brain networks contributing to the Parieto-Frontal Integration Theory of Intelligence. Neuroimage. 2014;103:349-54. doi: 10.1016/j.neuroimage.2014.09.055. [PubMed: 25284305].

6. Banich MT, Belger A. Interhemispheric interaction: How do the hemispheres divide and conquer a task? Cortex. 1990;26(1):77-94. doi: 10.1016/s0010-9452(13)80076-7. [PubMed: 2354647].

7. Banich MT, Brown WS. A life-span perspective on interaction between the cerebral hemispheres. Dev Neuropsychol. 2000;18(1):1-10. doi:10.1207/S15326942DN1801_1. [PubMed: 11143800].

8. Hutchinson AD, Mathias JL, Jacobson BL, Ruzic L, Bond AN, Banich MT. Relationship between intelligence and the size and composition of the corpus callosum. Exp Brain Res. 2009;192(3):455-64. doi: 10.1007/s00221-008-1604-5. [PubMed: 18949469].

9. Schatz J, Buzan R. Decreased corpus callosum size in sickle cell disease: Relationship with cerebral infarcts and cognitive functioning. $J$ Int Neuropsychol Soc. 2006;12(1):24-33. doi:10.1017/S1355617706060085. [PubMed: 16433941].

10. Mihrshahi R. The corpus callosum as an evolutionary innovation. J Exp Zool B Mol Dev Evol. 2006;306(1):8-17. doi: 10.1002/jez.b.21067. [PubMed: 16116611].

11. Winter TJ, Franz EA. Implication of the anterior commissure in the allocation of attention to action. Front Psychol. 2014;5:432. doi: 10.3389/fpsyg.2014.00432. [PubMed: 24904456]. [PubMed Central: PMC4032986].

12. Patel MD, Toussaint N, Charles-Edwards GD, Lin JP, Batchelor PG. Distribution and fibre field similarity mapping of the human anterior commissure fibres by diffusion tensor imaging. MAGMA. 2010;23(56):399-408. doi: 10.1007/s10334-010-0201-3. [PubMed: 20229087].

13. Strauss E, Wada J, Hunter M. Callosal morphology and performance on intelligence tests. J Clin Exp Neuropsychol. 1994;16(1):79-83. doi: 10.1080/01688639408402618. [PubMed: 8150891].

14. Spencer MD, Gibson RJ, Moorhead TWJ, Keston PM, Hoare P, Best JJK, et al. Qualitative assessment of brain anomalies in adolescents with mental retardation. Am J Neuroradiol. 2005;26(10):2691-7.

15. Hofer S, Frahm J. Topography of the human corpus callosum revisited-comprehensive fiber tractography using diffusion tensor magnetic resonance imaging. Neuroimage. 2006;32(3):989-94. doi: 10.1016/j.neuroimage.2006.05.044. [PubMed: 16854598].

16. Luders E, Narr KL, Bilder RM, Thompson PM, Szeszko PR, Hamilton L, et al. Positive correlations between corpus callosum thickness and intelligence. Neuroimage. 2007;37(4):1457-64. doi: 10.1016/j.neuroimage.2007.06.028. [PubMed: 17689267]. [PubMed Central: PMC2754582].

17. Wozniak JR, Muetzel RL, Mueller BA, McGee CL, Freerks MA, Ward EE, et al. Microstructural corpus callosum anomalies in children with prenatal alcohol exposure: an extension of previous diffusion tensor imaging findings. Alcohol Clin Exp Res. 2009;33(10):1825-35. doi: 10.1111/j.1530-0277.2009.01021.x. [PubMed: 19645729]. [PubMed Central: PMC2895908].

18. Westerhausen R, Friesen CM, Rohani DA, Krogsrud SK, Tamnes CK, Skranes JS, et al. The corpus callosum as anatomical marker of intelligence? A critical examination in a large-scale developmental study. Brain Struct Funct. 2018;223(1):285-96. doi: 10.1007/s00429-017-1493-0. [PubMed: 28801753]. [PubMed Central: PMC5772147].

19. Allin M, Nosarti C, Narberhaus A, Walshe M, Frearson S, Kalpakidou A, et al. Growth of the corpus callosum in adolescents born preterm. Arch Pediatr Adolesc Med. 2007;161(12):1183-9. doi: 10.1001/archpedi.161.12.1183. [PubMed: 18056564].

20. Katz MJ, Lasek RJ, Silver J. Ontophyletics of the nervous system: Development of the corpus callosum and evolution of axon tracts. Proc Natl Acad Sci U S A. 1983;80(19):5936-40. doi: 10.1073/pnas.80.19.5936. [PubMed: 6577462]. [PubMed Central: PMC390192].

21. Ashwell K. The neurobiology of Australian marsupials: Brain evolution in the other mammalian radiation. Cambridge University Press; 2010.

22. Saxena K, Tamm L, Walley A, Simmons A, Rollins N, Chia J, et al. A preliminary investigation of corpus callosum and anterior commissure aberrations in aggressive youth with bipolar disorders. J Child Adolesc Psychopharmacol. 2012;22(2):112-9. doi: 10.1089/cap.2011.0063. [PubMed: 22375854]. [PubMed Central: PMC3362324].

23. Keats TE, Sistrom C. Atlas of radiologic measurement. Gulf Professional Publishing; 2001.

24. Mohammadi MR, Zhand P, Mortazavi Moghadam B, Golalipour MJ. Measurement of the corpus callosum using magnetic resonance imaging in the north of Iran. Iran J Radiol. 2011;8(4):218-23. doi: 10.5812/iranjradiol.4495. [PubMed: 23329944]. [PubMed Central: PMC3522367].

25. Groth-Marnat G, Gallagher RE, Hale JB, Kaplan E. Neuropsychological assessment in clinical practice: A guide to test interpretation and integration. New York: Wiley and Sons; 2000.

26. Abedi MR. Standardization of Wechsler Adult Intelligence Scale-R (WAISR) [dissertation]. Tehran: Psychiatric Institute, Iran University of Medical Sciences; 1994.

27. Pfleiderer B, Ohrmann P, Suslow T, Wolgast M, Gerlach AL, Heindel $\mathrm{W}$, et al. N-acetylaspartate levels of left frontal cortex are associated with verbal intelligence in women but not in men: A proton magnetic resonance spectroscopy study. Neuroscience. 2004;123(4):1053-8. doi: 10.1016/j.neuroscience.2003.11.008. [PubMed:14751296].

28. Witelson SF, Beresh $\mathrm{H}$, Kigar DL. Intelligence and brain size in 100 postmortem brains: Sex, lateralization and age factors. Brain. 2006;129(Pt 2):386-98. doi: 10.1093/brain/awh696. [PubMed: 16339797].

29. Narr KL, Woods RP, Thompson PM, Szeszko P, Robinson D, Dimtcheva T, et al. Relationships between IQ and regional cortical gray matter thickness in healthy adults. Cereb Cortex. 2007;17(9):2163-71. doi: 10.1093/cercor/bhl125. [PubMed: 17118969].

30. Ardekani BA, Figarsky K, Sidtis JJ. Sexual dimorphism in the human corpus callosum: An MRI study using the OASIS brain database. Cereb Cortex. 2013;23(10):2514-20. doi: 10.1093/cercor/bhs253. [PubMed: 22891036]. [PubMed Central: PMC3767965].

31. Shiino A, Chen YW, Tanigaki K, Yamada A, Vigers P, Watanabe T, et al. Sex-related difference in human white matter volumes studied: Inspection of the corpus callosum and other white matter by 
VBM. Sci Rep. 2017;7:39818. doi:10.1038/srep39818.[PubMed: 28045130] [PubMed Central: PMC5206615].

32. Vannucci RC, Barron TF, Vannucci SJ. Development of the corpus callosum: An MRI study. Dev Neurosci. 2017;39(1-4):97-106. doi 10.1159/000453031. [PubMed: 28013305].

33. Anderson LB, Paul LK, Brown WS. Emotional intelligence in agenesis of the corpus callosum. Arch Clin Neuropsychol. 2017;32(3):267-79. doi: 10.1093/arclin/acx001. [PubMed: 28431033].

34. Guenot M. [Interhemispheric transfer and agenesis of the corpus callosum. Capacities and limitations of the anterior commissure]. Neurochirurgie. 1998;44(1 Suppl):113-5. French. [PubMed: 9757333]. 